\title{
Integrative genomic analyses of recepteur d'origine nantais and its prognostic value in cancer
}

\author{
HAIZHONG YU $^{1}$, JIANFEN YUAN ${ }^{1}$, CHUNHONG XIAO $^{2}$ and YI QIN $^{1}$ \\ ${ }^{1}$ Department of Clinical Laboratory of the Traditional Chinese Medical Hospital of Nantong City; \\ ${ }^{2}$ Department of Clinical Laboratory of Nantong Tumor Hospital, Nantong, Jiangsu, P.R. China
}

Received December 12, 2012; Accepted February 21, 2013

DOI: $10.3892 /$ ijmm.2013.1296

\begin{abstract}
Recepteur d'origine nantais (RON) is a receptor tyrosine kinase (RTK) normally expressed at low levels in epithelial cells. RON is a $180-\mathrm{kDa}$ heterodimeric protein composed of a 40-kDa $\alpha$-chain and a $150-\mathrm{kDa}$ transmembrane $\beta$-chain with intrinsic tyrosine kinase activity. The extracellular sequences of RON contain several domains including an N-terminal semaphorin (sema) domain, followed by the plexin, semaphorin, integrin (PSI) domain, and four immunoglobulin, plexin, transcription factor (IPT) domains. Here, we identified RON genes from 14 vertebrate genomes and found that RON exists in all types of vertebrates including fish, amphibians, birds and mammals. We found that the human RON gene showed predominant expression in the liver, lymph node, thymus, intestine, lung, mammary gland, bone marrow, brain, heart, placenta, bladder, cortex, cervix, skin, kidney and prostate. When searched in the PrognoScan database, human RON was also found to be expressed in bladder, blood, breast, glioma, esophageal, colorectal, head and neck, ovarian, lung and skin cancer. The relationship between the expression of RON and prognosis was found to vary in different cancer types, even in the same cancer from different databases. This suggests that the function of RON in these tumors may be multidimensional, not just as a tumor suppressor or oncogene. Six available single-nucleotide polymorphisms (SNPs) disrupting existing exonic splicing enhancers were identified in RON. This may contribute to the generation of active RON variants by alternative splicing, which is frequently observed in primary tumors.
\end{abstract}

\section{Introduction}

Recepteur d'origine nantais (RON) is a receptor tyrosine kinase (RTK) normally expressed at low levels mostly in

Correspondence to: Professor Haizhong Yu, Department of Clinical Laboratory of Traditional Chinese Medical Hospital of Nantong City, 41 Jianse Road, Nantong, Jiangsu 226001, P.R. China E-mail: huizhongyu999@gmail.com

Key words: recepteur d'origine nantais, comparative genomics, comparative proteomics, cancer, prognosis, meta-analysis epithelial cells $(1,2)$. The human RON gene was originally cloned from keratinocytes (1). It contains 20 exons and 19 introns and is located on chromosome 3p21 (1-3), a region frequently altered in certain cancer types (4). The RON cDNA encodes 1,400 amino acids, which are synthesized first as a single-chain precursor (pro-RON) (1). Maturation occurs in the cell membrane resulting in a $180-\mathrm{kDa}$ heterodimeric protein composed of a $40-\mathrm{kDa} \alpha$-chain and a $150-\mathrm{kDa}$ transmembrane $\beta$-chain with intrinsic tyrosine kinase activity $(5,6)$. The extracellular sequences of RON contain several domains including an N-terminal semaphorin (sema) domain, followed by the plexin, semaphorin, integrin (PSI) domain, and four immunoglobulin, plexin, transcription factor (IPT) domains (7).

$\mathrm{RON}$ is activated in response to macrophage-stimulating protein (MSP), and then induces an invasive program (8) consisting of cell proliferation, migration, and invasion, all of which are important at multiple points during tumorigenesis. RON gene transcripts are present in the liver, lung, brain, kidney, bone, adrenal glands, testis and digestive tract (2). RON was found to be primarily expressed in cells of epithelial origin such as colon, breast and skin (9). Constitutively active RON variants may be generated by alternative splicing (RON $\Delta 165$, RON $\Delta 160$, and RON $\Delta 155$ ) or by methylationdependent promoter usage [short form RON (sfRON)] $(10,11)$. Among these RON variants, RON $\Delta 160$ is located at the plasma membrane, whereas RON $\Delta 165$ and RON $\Delta 155$ are retained in the cytoplasm. sfRON lacks almost all of the extracellular domain and is incapable of ligand binding. Recent studies have indicated that altered RON expression contributes significantly to cancer progression and malignancy. In primary tumors, such as colon and breast cancers, overexpression of RON exists in a large number of cases and is often accompanied by the generation of different splicing variants (12-14). However, a comprehensive investigation of whether RON is involved in the formation of various types of tumors has not been adequately carried out.

In the present study, we identified RON genes in the human, chimpanzee, macaque, orangutan, dog, cow, horse, mouse, rat, opossum, chicken, Xenopus tropicalis, zebrafish, and fugu by comparative genomic analyses. Conserved transcription factor-binding sites within promoter regions of human RON genes were then searched. The expression data, functional relevant single-nucleotide polymorphisms 


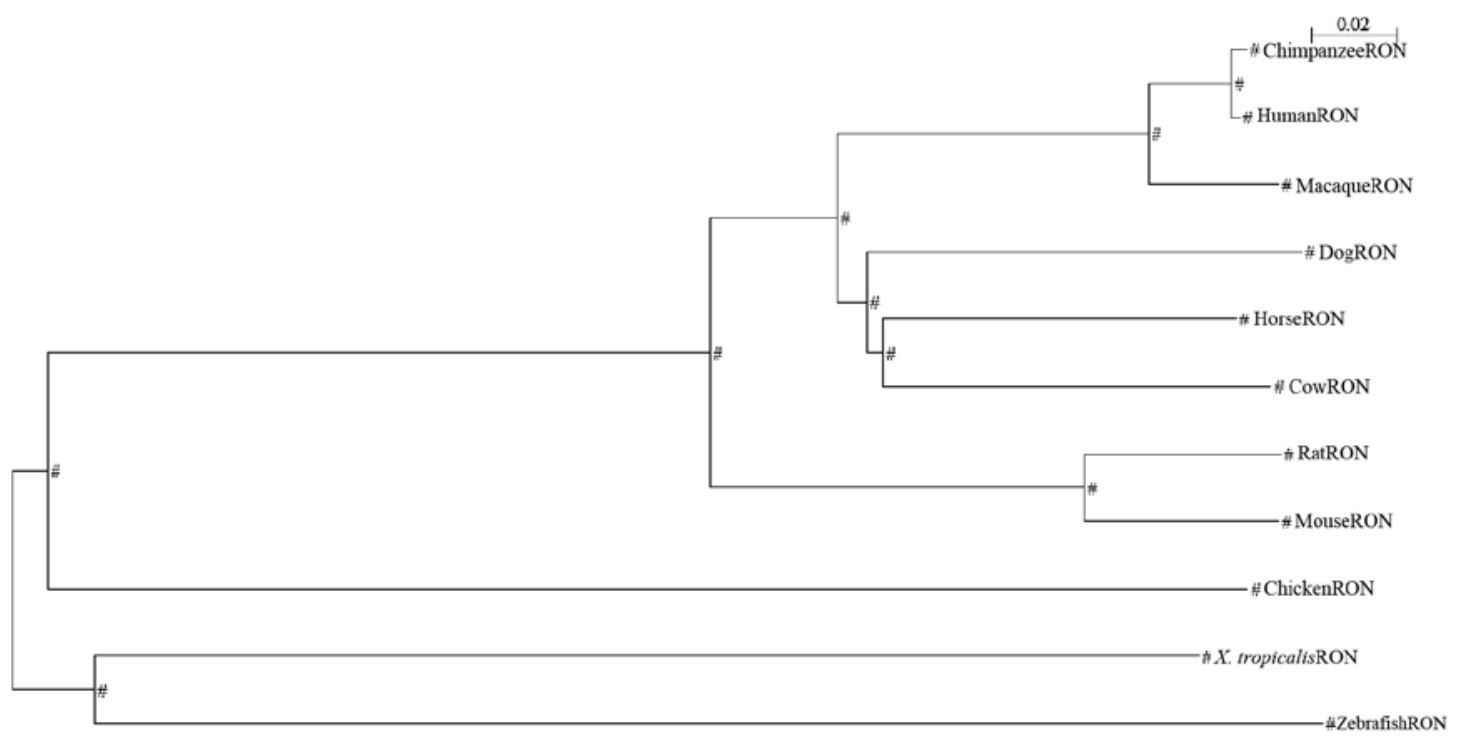

Figure 1. Phylogenetic analysis of RON. RON genes were identified in the genome sequences of the human, chimpanzee, macaque, orangutan, dog, cow, horse, mouse, rat, opossum, chicken, Xenopus tropicalis, zebrafish and fugu. The phylogenetic tree of the RON gene was obtained using maximum likelihood and neighbor-joining methods. It appeared that primate RON was clustered into one group, different from other RON genes.

(SNPs) and comparative proteomic analyses were conducted. Furthermore, meta-analysis of the prognostic value of RON genes in various cancers was also performed.

\section{Materials and methods}

Identification of novel RON genes in vertebrate genomes and integrative genomic analyses. RON genes were searched in the genome sequences of the human (Homo sapiens), chimpanzee (Pan troglodytes), macaque (Macaca mulatta), orangutan (Pongo pygmaeus), dog (Canis familiaris), cow (Bos taurus), horse (Equus caballus), mouse (Mus musculus), rat (Rattus norvegicus), opossum (Monodelphis domestica), chicken (Gallus gallus), Xenopus tropicalis, zebrafish (Danio rerio), and fugu (Takifugu rubripes) by standard methods using the human RON gene (NM_002447) as a query. The assemblies used were human NCBI 36, chimpanzee CHIMP2.1, macaque MMUL 1.0, orangutan PPYG2, dog CanFam 2.0, cow Btau 4.0, horse Equ Cab 2, mouse NCBI m37, rat RGSC 3.4, opossum monDom5, chicken WASHUC2, X. tropicalis JGI 4.1, zebrafish Zv8 and fugu FUGU 4.0. The identified putative Ikaros genes were BLASTed against the nr database of GenBank to confirm that the best hits were RON genes (15-17). Conserved transcription factor-binding sites within the promoter region of the human RON gene was obtained from SABiosciences proprietary database which combines Text Mining Application and data from the UCSC Genome Browser.

Comparative proteomic analyses of RON proteins. The amino acid sequences of RON were deduced from the identified RON genes and aligned using Clustal X 1.8 software (18). The phylogenetic tree of RON was obtained by using maximum likelihood (ML) (PHYML v2.4.4) (19) and neighbor-joining (NJ) (MEGA 3.0) (20) methods, and the reliability of the tree was evaluated by the bootstrap method with 1,000 replica- tions. The program Codeml implemented in the PAML $3.14 \mathrm{~b}$ software package was used to investigate whether Ikaros proteins are under positive selection (21). Six models of codon substitution, M0 (one-ratio), M1a (nearly neutral), M2a (positive selection), M3 (discrete), M7 ( $\beta$ ), and M8 ( $\beta$ and $\omega)$ were used in the analysis (22).

Functional relevant SNP evaluation of the human RON gene. Functional relevant SNPs of the human RON gene were identified as previously described (15). The SNPs were extracted from Ensembl (http://www.ensembl.org) and NCBI's SNPdb (http://www.ncbi.nlm.nih.gov). The SNPs that could disrupt exonic splicing enhancer/exonic splicing silencer (ESE/ESS) motifs and cause a missense mutation were also identified.

In silico expression analyses of the human RON gene. Expressed sequence tags (ESTs) derived from the human RON gene were searched using the BLAST programs as previously described (23-28). Human RON gene (NM_002447) was used as query sequences for the BLAST programs. The expression profiles for normal human tissues were obtained from GeneAnnot (29) and ArrayExpress (30). Northern analysis of NCBI's uniGene dataset was also extracted (15).

Meta-analysis of the prognostic value of the RON gene in cancer. A database named 'PrognoScan' has been developed (31). This is i) a large collection of publicly available cancer microarray datasets with clinical annotations, as well as ii) a tool for assessing the biological relationship between gene expression and prognosis. PrognoScan employs the minimum P-value approach for grouping patients for survival analysis. PrognoScan provides a powerful platform for evaluating potential tumor markers and therapeutic targets and is publicly accessible at http://gibk21.bio.kyutech.ac.jp/PrognoScan/index. html. Human RON (MST1R) gene was input as a query and the data were collected for analysis. 
Table I. Evaluation of the functionally relevant SNPs of the human RON gene.

\begin{tabular}{|c|c|c|c|}
\hline SNP ID & Chr 3 position & Sequence & Type \\
\hline rs 1062633 & 49924940(-) & CCTTCA/GGAGTA & Missense \\
\hline rs 2230590 & 49936102(-) & TATCCA/C/G/TAGGCC & Missense \\
\hline rs2230593 & 49940078(-) & GCTGCA/C/G/TGGTGG & Missense \\
\hline rs13078735 & 49933274(+) & CCGCAC/TCACTC & Missense \\
\hline rs2230591 & 49936626(-) & СТTCTC/TACGTG & Missense \\
\hline rs2230592 & 49936608(-) & ATTCAA/C/G/TTGGGC & Missense \\
\hline rs34350470 & $49936338(+)$ & AAGACA/GACTGA & Missense \\
\hline rs7433231 & 49928691(+) & CATGCC/TGCGGG & Missense \\
\hline rs35986685 & $49935526(+)$ & GACTTG/TGGCCC & Missense \\
\hline rs34564898 & $49936533(+)$ & TTGTGC/TCCATG & Missense \\
\hline rs35887539 & $49940820(+)$ & ATTGCG/TTATGG & Missense \\
\hline rs56330223 & 49924864(+) & TCATGC/TAGGTT & Missense \\
\hline rs56091918 & $49933492(+)$ & ACCCAC/TGGTCA & Missense \\
\hline rs55633379 & $49940490(+)$ & TACACA/GGGTGC & Missense \\
\hline rs3733136 & 49940706(+) & AGGGCC/TGTGGG & Missense \\
\hline rs61729096 & $49933469(+)$ & AACTCC/TTGCTG & Missense \\
\hline rs55908300 & $49940760(+)$ & AGCAGG/TGCCCG & Missense \\
\hline rs56066753 & $49924837(+)$ & TCTCAC/TGCGAG & Missense \\
\hline rs35924402 & 49939976(+) & GACCAC/TCATCC & Missense \\
\hline rs34740617 & $49928852(+)$ & ATGAA-/ACTGGA & Frameshift \\
\hline rs34211295 & $49936120(+)$ & GAAAA-/TCCTGT & Frameshift \\
\hline rs66570013 & $49933436(+)$ & GGGGC-/GAGGGG & Frameshift \\
\hline rs66589847 & $49933500(+)$ & TCACG-/TTGATA & Frameshift \\
\hline rs67360293 & $49934262(+)$ & CTAAG-/GGGGGA & Frameshift \\
\hline rs67811243 & 49932778(+) & GTGGT-/GGAATC & Frameshift \\
\hline rs 1062633 & $49924940(-)$ & CCTTCA/GGAGTA & Exonic splicing enhancer \\
\hline rs2230591 & $49936626(-)$ & СTTCTC/TACGTG & Exonic splicing enhancer \\
\hline rs2230592 & 49936608(-) & ATTCAA/GTGGGC & Exonic splicing enhancer \\
\hline rs2230593 & 49940078(-) & GCTGCG/AGGTGG & Exonic splicing enhancer \\
\hline rs3733136 & $49940706(+)$ & AGGGCC/TGTGGG & Exonic splicing enhancer \\
\hline rs13318943 & 49940499(+) & GCCCAA/GTGGGC & Exonic splicing enhancer \\
\hline
\end{tabular}

A total of 380 available SNPs were identified in the human RON gene. Among these, 33 SNPs were functionally relevant, including 5 available alleles disrupting an existing exonic splicing enhancer, 21 SNPs causing a missense mutation and 6 frame shift SNPs.

\section{Results}

Comparative proteomics of RON proteins identified in vertebrate genomes. RON genes were identified in the genome sequences of the human, chimpanzee, macaque, orangutan, dog, cow, horse, mouse, rat, opossum, chicken, Xenopus tropicalis, zebrafish and fugu. Refined phylogenetic trees using the identified RON protein amino acid sequences by ML and NJ methods were almost identical (Fig. 1). We were unable to identify any site under positive selection with any of the 6 models in RON proteins. Instead, the RON proteins were under purifying selection (data not shown).

Expression profile of the human RON gene. By EST sequence searching, the human RON gene was expressed in prostate, colon, stomach, an adenocarcinoma cell line, kidney, B-cells of chronic lymphatic leukemia, squamous cell carcinoma, testis, thalamus, thymus, uterus, transitional cell papilloma, brain, liver, coronary artery smooth cells, human retinal pigment epithelium and epithelial. The investigation of available microarray experiments and 'virtual northern blotting' showed a predominant expression of RON in the liver, lymph node, thymus, intestine, lung, mammary gland, bone marrow, brain, heart, placenta, bladder, cortex, cervix, skin, kidney and prostate. When searched in PrognoScan database, human RON was also found to be expressed in bladder cancer, blood cancer, breast cancer, glioma, esophageal cancer, colorectal cancer, head and neck cancer, ovarian cancer, lung cancer and skin cancer tissues.

Comparative genomics of the human RON gene. NF- $\mathrm{B}$, signal transducer and activator of transcription 5A (STAT5A), signal transducer and activator of transcription 3 (STAT3), $\mathrm{C} / \mathrm{EBP} \alpha, \mathrm{ZID}$, peroxisome proliferator-activated receptor (PPAR)- $\gamma$, serum response factor (SRF), POU domain, class 2 , transcription factor 1 (POU2F1) regulatory transcription factor 


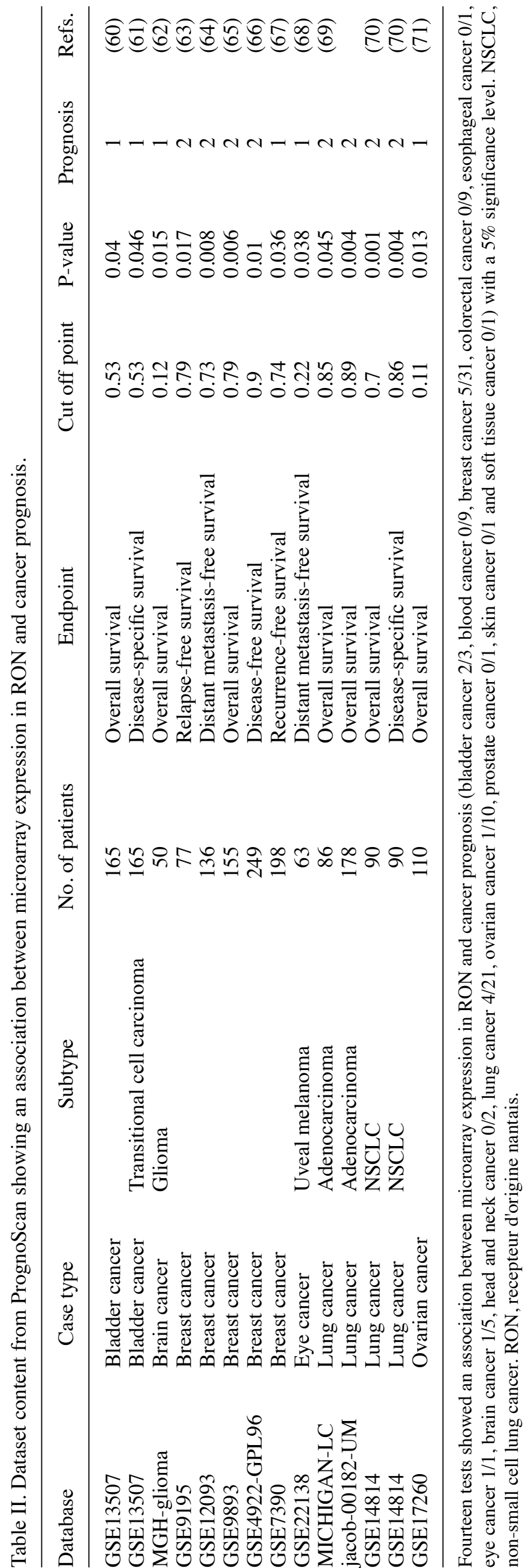

binding sites were identified in the MST1R gene upstream (promoter) region.

Functional relevant SNP evaluation of the human RON gene. Three hundred and eighty available SNPs were identified in human RON gene. Among these, 33 SNPs were functionally relevant, including five available alleles disrupted an existing exonic splicing enhancer and 21 SNPs causing missense mutation. Moreover, six frame shift SNPs were also found (Table I)

Meta-analysis of the prognostic value of the human RON gene in cancer. PrognoScan displays a summary in table format of tests for the specific gene with columns for dataset, cancer type, subtype, endpoint, cohort, contributor, array type, probe ID, number of patients, optimal cut-off point, Pmin and Pcor. Among the databases which detected the expression of the RON gene, 14 out of 97 tests showed an association between microarray expression in the RON gene and cancer prognosis (bladder cancer $2 / 3$, blood cancer $0 / 9$, breast cancer $5 / 31$, colorectal cancer $0 / 9$, esophageal cancer $0 / 1$, eye cancer $1 / 1$, brain cancer $1 / 5$, head and neck cancer $0 / 2$, lung cancer $4 / 21$, ovarian cancer $1 / 10$, prostate cancer $0 / 1$, skin cancer $0 / 1$ and soft tissue cancer $0 / 1$ ) with a $5 \%$ significance level (Table II). Of the 6 breast cancer cases, higher expression of the RON gene was found to relate to poor survival in 4 cases (GSE9195, GSE12093, GSE9893 and GSE4922). However, low expression of the RON gene was related to poor survival in 2 cases of breast cancer (GSE7390). Regarding lung cases, we found a higher expression of the RON gene to be associated with poor survival in all 4 lung cancer cases including adenocarcinoma and NSCLC. In the other cancer cases, a low expression of the RON gene was associated with poor survival in 2 cases of bladder cancer, 1 case of brain cancer, eye cancer and ovarian cancer.

\section{Discussion}

RON is a RTK containing 20 exons and 19 introns. It is located on chromosome 3p21 (1-3) in the human genome, a region frequently altered in certain cancers (4). In the present study, we identified other RON genes from an additional 13 vertebrate genomes and found that RON exists in all types of vertebrates including fish, amphibians, birds and mammals. Moreover, all identified RON proteins contain the semaphorin (sema) domain, followed by the PSI domain, and four IPT domains. The phylogenetic tree showed that RON is separated according to the order fish, amphibians, birds and mammals. Primate RONs are almost identical and clustered together. From the alignment and phylogenetic tree, mammalian RONs are conserved among vertebrate genomes, suggesting that the function of RON is essential for all vertebrates during the long evolutionary process. Moreover, this process was under purifying selection.

In adult tissues, RON expression has been found in brain, adrenal glands, epithelium of the gastrointestinal tract, testis, kidneys and ovaries (2). Systematic analysis of RON expression in normal tissues and cancer samples has not been adequately carried out. In general, RON has been detected in certain types of normal cells such as epithelial cells and 
tissue macrophages. We found that the human RON gene was expressed in many tissue or organs. It showed predominant expression in the liver, lymph node, thymus, intestine, lung, mammary gland, bone marrow, brain, heart, placenta, bladder, cortex, cervix, skin, kidney and prostate.

Ligand-dependent or -independent activation of RON results in cell proliferation, migration, and matrix invasion, collectively known as invasive growth $(32,33)$. These activities facilitate epithelial cell transformation and malignant progression. Elevated RON expression has been found in breast, colon, lung, bladder and ovarian cancer (34-40). In the present study, we found predominant expression of RON in the liver, lymph node, thymus, intestine, lung, mammary gland, bone marrow, brain, heart, placenta, bladder, cortex, cervix, skin, kidney and prostate by the investigation of available microarray experiments and 'virtual northern blotting' as shown. When searched in the PrognoScan database, human RON was also found to be expressed in bladder cancer, blood cancer, breast cancer, glioma, esophageal cancer, colorectal cancer, head and neck cancer, ovarian cancer, lung cancer and skin cancer tissues.

Wang et al (41) reported that the roles of RON in cancer pathogenesis are as follows. First, aberrant splicing, resulting in the formation of oncogenic RON variants, is frequently observed in primary tumors such as colon and breast cancers. Second, RON overexpression exists in various types of primary and metastatic tumors, indicating that RON overexpression is involved in tumorigenic progression. Third, RON activation promotes a malignant phenotype in cancer cells. Fourth, altered RON expression results in increased survival and pro-apoptotic activity of tumor cells, which sustains tumor growth under hostile conditions such as hypoxia. Fifth, abnormality in RON expression contributes to the acquired resistance to conventional chemoagents. Therefore, various strategies have been reported to block the c-MET/RON pathways for targeted cancer treatment (42-45). Aberrant RON expression is featured by generation of biologically active RON variants (46). Currently, seven RON variants including RON $\Delta 170$, RON $\Delta 165$, RON $\Delta 160$, RON $\Delta 155$, RON $\Delta p 110$, RON $\Delta 85$ and RON $\Delta 52$ have been identified in primary cancer samples and in established cell lines (46). The switch from constitutive to alternative pre-mRNA splicing is the major event in producing RON variants in cancer cells. These RON variants have the ability to activate multiple signaling cascades, and consequently regulate cell migration, invasion and proliferation, which contribute to the invasive phenotype and promote malignant progression (12). We identified 5 available SNPs disrupting an existing exonic splicing enhancer, which may affect the alternative splicing of the RON gene. The effects of these SNPs on RON physiological and pathological function warrant further investigation. We also identified 21 SNPs causing a missense mutation and 6 frame shift SNPs. Although RON gene mutations were not found in primary cancer samples, these mutations of RON warrant further observation.

In the present study, in regards to the 5 breast cancers, high expression of the RON gene was associated with poor survival in 4 cases. However, low expression of the RON gene was related to poor survival in 1 cases of breast cancer. Concerning lung case, high expression of the RON gene was associated with poor survival in all 4 lung cancer cases including adenocarcinoma and NSCLC. In the other cancer cases, low expression of the RON gene was associated with poor survival in 2 cases of bladder cancer, 1 case of brain cancer, eye cancer and ovarian cancer. This suggests that the expression of RON is related to the prognosis of many solid tumors. The mechanism of RON involved in the process of these tumors requires further investigation. It is important to note that the relationship between the expression of RON and prognosis varied in different types of cancers, even in the same cancer from different databases. This implies that the function of RON in these tumors may be multidimensional, not just as a tumor suppressor or oncogene.

NF- $\kappa$ B, STAT5A, STAT3, PPAR- $\gamma$, SRF, POU2F1 regulatory transcription factor binding sites were identified in the MST1R gene upstream (promoter) region. NF- $\kappa \mathrm{B}$ is widely used by eukaryotic cells as a regulator of genes that control cell proliferation and cell survival. As such, many different types of human tumors have misregulated $N F-\kappa B$ : that is, $N F-\kappa B$ is constitutively active. Active NF- $\kappa B$ turns on the expression of genes that maintains cell proliferation and protects the cell from conditions that would otherwise cause it to die via apoptosis (47-50). Constitutively activated STAT proteins, in particular STAT3 and STAT5, have been demonstrated to directly contribute to oncogenesis, in part, by stimulating proliferation and preventing apoptosis in various types of tumor cells (51-53). SRF is a member of the MADS box family of transcription factors. It was recently shown that SRF is involved in the epithelial-mesenchymal transition (EMT) of various types of cancer and it regulates migration and invasion of these cells with subsequent acquisition of the mesenchymal phenotype (54-56). PPAR- $\gamma$ belongs to the family of nuclear hormone receptors (NHRs), which directly regulate transcription of target genes. PPAR- $\gamma$ activation by specific agonists leads to growth inhibition, apoptosis and differentiation of tumor cells (57-59). These two tumor-related transcriptional factors may be involved in the effect of RON on tumors.

\section{References}

1. Ronsin C, Muscatelli F, Mattei MG and Breathnach R: A novel putative receptor protein tyrosine kinase of the met family. Oncogene 8: 1195-1202, 1993.

2. Gaudino G, Avantaggiato V, Follenzi A, Acampora D, Simeone A and Comoglio PM: The proto-oncogene RON is involved in development of epithelial, bone and neuro-endocrine tissues. Oncogene 11: 2627-2637, 1995.

3. Angeloni D, Danilkovitch-Miagkova A, Ivano SV, Breathnach R, Johnson BE, Leonard EJ and Lerman MI: Gene structure of the human receptor tyrosine kinase RON and mutation analysis in lung cancer samples. Genes Chromosomes Cancer 29: 147-156, 2000

4. Zabarovsky ER, Lerman MI and Minna JD: Tumor suppressor genes on chromosome $3 p$ involved in the pathogenesis of lung and other cancers. Oncogene 21: 6915-6935, 2002.

5. Gaudino G, Follenzi A, Naldini L, et al: RON is a heterodimeric tyrosine kinase receptor activated by the HGF homologue MSP. EMBO J 13: 3524-3532, 1994.

6. Wang MH, Ronsin C, Gesnel MC, Coupey L, Skeel A, Leonard EJ and Breathnach R: Identification of the ron gene product as the receptor for the human macrophage stimulating protein. Science 266: 117-119, 1994.

7. Stella GM, Benvenuti S and Comoglio PM: Targeting the MET oncogene in cancer and metastases. Expert Opin Investig Drugs 19: $1381-1394,2010$ 
8 Medico E, Mongiovi AM, Huff J, Jelinek MA, Follenzi A, Gaudino G, Parsons JT and Comoglio PM: The tyrosine kinase receptors Ron and Sea control 'scattering' and morphogenesis of liver progenitor cells in vitro. Mol Biol Cell 7: 495-504, 1996.

9. Wang MH, Lee W, Luo YL, Weis MT and Yao HP: Altered expression of the RON receptor tyrosine kinase in various epithelial cancers and its contribution to tumourigenic phenotypes in thyroid cancer cells. J Pathol 213: 402-411, 2007.

10. Camp ER, Yang A, Gray MJ, Fan F, Hamilton SR, Evans DB, Hooper AT, Pereira DS, Hicklin DJ and Ellis LM: Tyrosine kinase receptor RON in human pancreatic cancer: expression, function, and validation as a target. Cancer 109: 1030-1039, 2007.

11. Ghigna C, Giordano S, Shen H, Benvenuto F, Castiglioni F, Comoglio PM, Green MR, Riva S and Biamonti G: Cell motility is controlled by SF2/ASF through alternative splicing of the Ron protooncogene. Mol Cell 20: 881-890, 2005.

12. Lu Y, Yao HP and Wang MH: Multiple variants of the RON receptor tyrosine kinase: biochemical properties, tumorigenic activities, and potential drug targets. Cancer Lett 257: 157-164, 2007.

13. Moon H, Cho S, Yang X, Zhou J, Loh TJ, Zheng X and Shen $\mathrm{H}$ Identification of novel splicing variants from RON protooncogene pre-mRNA. Oncol Rep 28: 2217-2220, 2012.

14. Okino T, Egami H, Ohmachi H, Takai E, Tamori Y, Nakagawa K, Nakano S, Akagi J, Sakamoto O, Suda T and Ogawa M: Presence of RON receptor tyrosine kinase and its splicing variant in malignant and non-malignant human colonic mucosa. Int $\mathrm{J}$ Oncol 15: 709-714, 1999.

15. Yang L, Luo Y and Wei J: Integrative genomic analyses on Ikaros and its expression related to solid cancer prognosis. Oncol Rep 24: 571-577, 2010.

16. Yang L, Luo Y, Wei J and He S: Integrative genomic analyses on IL28RA, the common receptor of interferon- $\lambda 1,-\lambda 2$ and $-\lambda 3$. Int J Mol Med 25: 807-812, 2010.

17. Yang L, Wei J and He S: Integrative genomic analyses on interferon- $\lambda \mathrm{s}$ and their roles in cancer prediction. Int $\mathrm{J}$ Mol Med 25: 299-304, 2010

18. Thompson JD, Gibson TJ, Plewniak F, Jeanmougin F and Higgins DG: The CLUSTAL_X windows interface: flexible strategies for multiple sequence alignment aided by quality analysis tools. Nucleic Acids Res 15: 4876-4882, 1997.

19. Guindon S, Lethiec F, Duroux P and Gascuel O: PHYML Online - a web server for fast maximum likelihood-based phylogenetic inference. Nucleic Acids Res 33: W557-W559, 2005.

20. Kumar S, Tamura K and Nei M: MEGA3: Integrated software for Molecular Evolutionary Genetics Analysis and sequence alignment. Brief Bioinform 5: 150-163, 2004.

21. Yang Z: PAML: a program package for phylogenetic analysis by maximum likelihood. Comput Appl Biosci 13: 555-556, 1997.

22. Yang Z, Nielsen R, Goldman N and Pedersen AM: Codonsubstitution models for heterogeneous selection pressure at amino acid sites. Genetics 155: 431-449, 2000.

23. Katoh $Y$ and Katoh M: Integrative genomic analyses on GLI1: Positive regulation of GLI1 by Hedgehog-GLI, TGF 3 -Smads, and RTK-PI3K-AKT signals, and negative regulation of GLI1 by Notch-CSL-HES/HEY, and GPCR-Gs-PKA signals. Int J Oncol 35: 187-192, 2009.

24. Katoh $\mathrm{Y}$ and Katoh M: Integrative genomic analyses on GLI2: Mechanism of Hedgehog priming through basal GLI2 expression, and interaction map of stem cell signaling network with P53. Int J Oncol 33: 881-886, 2008.

25. Katoh $\mathrm{Y}$ and Katoh M: Integrative genomic analyses of WNT11: Transcriptional mechanisms based on canonical WNT signals and GATA transcription factors signaling. Int J Mol Med 24: 247-251, 2009.

26. Katoh M and Katoh M: Transcriptional mechanisms of WNT5A based on NF- $\kappa \mathrm{B}$, Hedgehog, TGF $\beta$, and Notch signaling cascades. Int J Mol Med 23: 763-769, 2009.

27. Katoh $\mathrm{M}$ and Katoh $\mathrm{M}$ : Integrative genomic analyses of ZEB2: Transcriptional regulation of ZEB2 based on SMADs, ETS1, HIF1 $\alpha$, POU/OCT, and NF- $\kappa B$. Int J Oncol 34: 1737-1742, 2009.

28. Katoh $\mathrm{M}$ and Katoh M: Transcriptional regulation of WNT2B based on the balance of Hedgehog, Notch, BMP and WNT signals. Int J Oncol 34: 1411-1415, 2009.

29. Chalifa-Caspi V, Yanai I, Ophir R, Rosen N, Shmoish M, Benjamin-Rodrig H, Shklar M, Stein TI, Shmueli O, Safran M and Lancet D: GeneAnnot: comprehensive two-way linking between oligonucleotide array probesets and GeneCards genes Bioinformatics 20: 1457-1458, 2004.
30. Parkinson H, Sarkans U, Shojatalab M, Abeygunawardena N, Contrino S, Coulson R, Farne A, Lara GG, Holloway E, Kapushesky M, Lilja P, Mukherjee G, Oezcimen A, Rayner T, Rocca-Serra P, Sharma A, Sansone S and Brazma A: ArrayExpress - a public repository for microarray gene expression data at the EBI. Nucleic Acids Res 33: D553-D555, 2005.

31. Mizuno H, Kitada K, Nakai K and Sarai A: PrognoScan: a new database for meta-analysis of the prognostic value of genes. BMC Med Genomics 2: 18, 2009.

32. Benvenuti S and Comoglio PM: The MET receptor tyrosine kinase in invasion and metastasis. J Cell Physiol 213: 316-325, 2007.

33. Wagh PK, Peace BE and Waltz SE: Met-related receptor tyrosine kinase Ron in tumor growth and metastasis. Adv Cancer Res 100: 1-33, 2008.

34. Maggiora P, Marchio S, Stella MC, Giai M, Belfiore A, De Bortoli M, Di Renzo MF, Costantino A, Sismondi P and Comoglio PM: Overexpression of the RON gene in human breast carcinoma. Oncogene 16: 2927-2933, 1998.

35. Park JS, Park JH, Lee S, Joo YE and Jung YD: Small interfering RNA targeting of Recepteur d'Origine Nantais induces apoptosis via modulation of nuclear factor- $\mathrm{\kappa B}$ and $\mathrm{Bcl}-2$ family in gastric cancer cells. Oncol Rep 24: 709-714, 2010.

36. Jiang WG, Ye L, Ablin RJ, Kynaston HG and Mason MD The prostate transglutaminase, TGase-4, coordinates with the HGFL/MSP-RON system in stimulating the migration of prostate cancer cells. Int J Oncol 37: 413-418, 2010.

37. Zhou YQ, He C, Chen YQ, Wang D and Wang MH: Altered expression of the RON receptor tyrosine kniase in primary human colorectal adenocarcinomas: generation of different splicing variants and their oncogenic potential. Oncogene 22: 186-197, 2003.

38. Lee WY, Chen HH, Chow NH, Su WC, Lin PW and Guo HR: Prognostic significance of co-expression of RON and MET receptors in node-negative breast cancer patients. Clin Cancer Res 11: 2222-2228, 2005.

39. Cheng HL, Liu HS, Lin YJ, Chen HH, Hsu PY, Chang TY, Ho CL, Tzai TS and Chow NH: Co-expression of RON and MET is a prognostic indicator for patients with transitional-cell carcinoma of the bladder. Br J Cancer 92: 1906-1914, 2005.

40. Maggiora P, Lorenzato A, Fracchioli S, Costa B, Castagnaro M, Arisio R, Katsaros D, Massobrio M, Comoglio PM and Flavia Di Renzo M: The RON and MET oncogenes are co-expressed in human ovarian carcinomas and cooperate in activating invasiveness. Exp Cell Res 288: 382-389, 2003.

41. Wang MH, Padhye SS, Guin S, Ma Q and Zhou YQ: Potential therapeutics specific to c-MET/RON receptor tyrosine kinases for molecular targeting in cancer therapy. Acta Pharmacol Sin 31: 1181-1188, 2010.

42. Cho SB, Park YL, Song YA, Kim KY, Lee GH, Cho DH, Myung DS, Park KJ, Lee WS, Chung IJ, Choi SK, Kim KK and Joo YE: Small interfering RNA-directed targeting of RON alters invasive and oncogenic phenotypes of human hepatocellular carcinoma cells. Oncol Rep 26: 1581-1586, 2011

43. Saigusa S, Toiyama Y, Tanaka K, Yokoe T, Fujikawa H, Matsushita K, Okugawa Y, Inoue Y, Uchida K, Mohri Y and Kusunoki M: Inhibition of HGF/cMET expression prevents distant recurrence of rectal cancer after preoperative chemoradiotherapy. Int J Oncol 40: 583-591, 2012.

44. Li Z, Yao H, Guin S, Padhye SS, Zhou YQ and Wang MH Monoclonal antibody (mAb)-induced down-regulation of RON receptor tyrosine kinase diminishes tumorigenic activities of colon cancer cells. Int J Oncol 37: 473-482, 2010.

45. Ma Q, Zhang K, Yao HP, Zhou YQ, Padhye S and Wang MH: Inhibition of MSP-RON signaling pathway in cancer cells by a novel soluble form of RON comprising the entire sema sequence. Int J Oncol 36: 1551-1561, 2010.

46. Ma Q, Zhang K, Guin S, Zhou YQ and Wang MH: Deletion or insertion in the first immunoglobulin-plexin-transcription (IPT) domain differentially regulates expression and tumorigenic activities of RON receptor tyrosine kinase. Mol Cancer 9: 307, 2010.

47. Parra E, Ferreira J and Saenz L: Inhibition of Egr-1 by siRNA in prostate carcinoma cell lines is associated with decreased expression of AP-1 and NF-кB. Int J Mol Med 28: 847-853, 2011.

48. Hwang JT, Park OJ, Lee YK, Sung MJ, Hur HJ, Kim MS, Ha JH and Kwon DY: Anti-tumor effect of luteolin is accompanied by AMP-activated protein kinase and nuclear factor- $\kappa \mathrm{B}$ modulation in HepG2 hepatocarcinoma cells. Int J Mol Med 28: 25-31, 2011. 
49. Seol JW, Lee YJ, Jackson CJ, Sambrook PN and Park SY: Activated protein $\mathrm{C}$ inhibits bisphosphonate-induced endothelial cell death via the endothelial protein $C$ receptor and nuclear factor- $\kappa$ B pathways. Int J Mol Med 27: 835-840, 2011.

50. Hayashi S, Sakurai H, Hayashi A, Tanaka Y, Hatashita M and Shioura $\mathrm{H}$ : Inhibition of NF- $\kappa \mathrm{B}$ by combination therapy with parthenolide and hyperthermia and kinetics of apoptosis induction and cell cycle arrest in human lung adenocarcinoma cells. Int J Mol Med 25: 81-87, 2010.

51. Hou L, Xu B, Mohankumar KM, Goffin V, Perry JK, Lobie PE and Liu DX: The prolactin receptor mediates HOXA1-stimulated oncogenicity in mammary carcinoma cells. Int $\mathbf{J}$ Oncol 41: 2285-2295, 2012.

52. Naher L, Kiyoshima T, Kobayashi I, Wada H, Nagata K, Fujiwara H, Ookuma YF, Ozeki S, Nakamura S and Sakai H: STAT3 signal transduction through interleukin-22 in oral squamous cell carcinoma. Int J Oncol 41: 1577-1586, 2012.

53. Umehara S, Fujiwara H, Shiozaki A, Todo M, Furutani A, Yoneda M, Ikai A, Tada H, Komatsu S, Ichikawa D, Okamoto K, Ochiai T, Kokuba Y and Otsuji E: PSK induces apoptosis through the inhibition of activated STAT3 in human esophageal carcinoma cells. Int J Oncol 41: 61-66, 2012.

54. Kwon CY, Kim KR, Choi HN, Chung MJ, Noh SJ, Kim DG, Kang MJ, Lee DG and Moon WS: The role of serum response factor in hepatocellular carcinoma: Implications for disease progression. Int J Oncol 37: 837-844, 2010.

55. Kim HJ, Kim KR, Park HS, Jang KY, Chung MJ, Shong M and Moon WS: The expression and role of serum response factor in papillary carcinoma of the thyroid. Int J Oncol 35: 49-55, 2009.

56. Park MY, Kim KR, Park HS, Park BH, Choi HN, Jang KY, Chung MJ, Kang MJ, Lee DG and Moon WS: Expression of the serum response factor in hepatocellular carcinoma: Implications for epithelial-mesenchymal transition. Int J Oncol 31: 1309-1315, 2007.

57. Collet N, Théoleyre S, Rageul J, Mottier S, Jouan F, RiouxLeclercq N, Fergelot P, Patard JJ, Masson D and Denis MG PPAR $\gamma$ is functionally expressed in clear cell renal cell carcinoma. Int J Oncol 38: 851-857, 2011.

58. Koga H, Selvendiran K, Sivakumar R, Yoshida T, Torimura T, Ueno $\mathrm{T}$ and Sata M: PPAR $\gamma$ potentiates anticancer effects of gemcitabine on human pancreatic cancer cells. Int J Oncol 40: 679-685, 2012

59. Mansour M, Schwartz D, Judd R, Akingbemi B, Braden T, Morrison E, Dennis J, Bartol F, Hazi A, Napier I and AbdelMageed AB: Thiazolidinediones/PPAR $\gamma$ agonists and fatty acid synthase inhibitors as an experimental combination therapy for prostate cancer. Int J Oncol 38: 537-546, 2011.

60. Kim WJ, Kim EJ, Kim SK, Kim YJ Ha YS, Jeong P, Kim MJ, Yun SJ, Lee KM, Moon SK, Lee SC, Cha EJ and Bae SC: Predictive value of progression-related gene classifier in primary non-muscle invasive bladder cancer. Mol Cancer 9: 3, 2010.

61. Lee JS, Leem SH, Lee SY, Kim SC, Park ES, Kim SB, Kim SK Kim YJ, Kim WJ and Chu IS: Expression signature of E2F1 and its associated genes predict superficial to invasive progression of bladder tumors. J Clin Oncol 28: 2660-2667, 2010.

62. Nutt CL, Mani DR, Betensky RA, Tamayo P, Cairncross JG, Ladd C, Pohl U, Hartmann C, McLaughlin ME, Batchelor TT, Black PM, von Deimling A, Pomeroy SL, Golub TR and Louis DN: Gene expression-based classification of malignant gliomas correlates better with survival than histological classification. Cancer Res 63: 1602-1607, 2003.
63. Loi S, Haibe-Kains B, Majjaj S, Lallemand F, Durbecq V, Larsimont D, Gonzalez-Angulo AM, Pusztai L, Symmans WF, Bardelli A, Ellis P, Tutt AN, Gillett CE, Hennessy BT, Mills GB, Phillips WA, Piccart MJ, Speed TP, McArthur GA and Sotiriou C: PIK3CA mutations associated with gene signature of low mTORC1 signaling and better outcomes in estrogen receptor-positive breast cancer. Proc Natl Acad Sci USA 107: 10208-10213, 2010.

64. Zhang Y, Sieuwerts AM, McGreevy M, Casey G, Cufer T, Paradiso A, Harbeck N, Span PN, Hicks DG, Crowe J, Tubbs RR, Budd GT, Lyons J, Sweep FC, Schmitt M, Schittulli F, Golouh R, Talantov D, Wang Y and Foekens JA: The 76-gene signature defines high-risk patients that benefit from adjuvant tamoxifen therapy. Breast Cancer Res Treat 116: 303-309, 2009.

65. Chanrion M, Negre V, Fontaine H, Salvetat N, Bibeau F MacGrogan G, Mauriac L, Katsaros D, Molina F, Theillet C and Darbon JM: A gene expression signature that can predict the recurrence of tamoxifen-treated primary breast cancer. Clin Cancer Res 14: 1744-1752, 2008.

66. Ivshina AV, George J, Senko O, Mow B, Putti TC, Smeds J, Lindahl T, Pawitan Y, Hall P, Nordgren H, Wong JE, Liu ET, Bergh J, Kuznetsov VA and Miller LD: Genetic reclassification of histologic grade delineates new clinical subtypes of breast cancer. Cancer Res 66: 10292-10301, 2006.

67. Desmedt C, Piette F, Loi S, Wang Y, Lallemand F, HaibeKains B, Viale G, Delorenzi M, Zhang Y, d'Assignies MS, Bergh J, Lidereau R, Ellis P, Harris AL, Klijn JG, Foekens JA, Cardoso F, Piccart MJ, Buyse M and Sotiriou C: TRANSBIG Consortium. Strong time dependence of the 76-gene prognostic signature for node-negative breast cancer patients in the TRANSBIG multicenter independent validation series. Clin Cancer Res 13: 3207-3214, 2007.

68. Laurent C, Valet F, Planque N, Silveri L, Maacha S, Anezo O, Hupe P, Plancher C, Reyes C, Albaud B, Rapinat A, Gentien D, Couturier J, Sastre-Garau X, Desjardins L, Thiery JP, RomanRoman S, Asselain B, Barillot E, Piperno-Neumann S and Saule S: High PTP4A3 phosphatase expression correlates with metastatic risk in uveal melanoma patients. Cancer Res 71: 666-674, 2011.

69. Beer DG, Kardia SL, Huang CC, Giordano TJ, Levin AM, Misek DE, Lin L, Chen G, Gharib TG, Thomas DG, Lizyness ML, Kuick R, Hayasaka S, Taylor JM, Iannettoni MD, Orringer MB and Hanash S: Gene-expression profiles predict survival of patients with lung adenocarcinoma. Nat Med 8: 816-824, 2002

70. Zhu CQ, Ding K, Strumpf D, Weir BA, Meyerson M, Pennell N, Thomas RK, Naoki K, Ladd-Acosta C, Liu N, Pintilie M, Der S, Seymour L, Jurisica I, Shepherd FA and Tsao MS: Prognostic and predictive gene signature for adjuvant chemotherapy in resected non-small-cell lung cancer. J Clin Oncol 28: 4417-4424, 2010.

71. Yoshihara K, Tajima A, Yahata T, Kodama S, Fujiwara H, Suzuki M, Onishi Y, Hatae M, Sueyoshi K, Fujiwara H, Kudo Y, Kotera K, Masuzaki H, Tashiro H, Katabuchi H, Inoue I and Tanaka K: Gene expression profile for predicting survival in advanced-stage serous ovarian cancer across two independent datasets. PLoS One 5: e9615, 2010. 